\title{
Phosphorus load in outdoor areas for laying hens and capacity of phosphorus retaining materials to reduce the environmental impact
}

\author{
Helena Aronsson (D) - Lotten Wahlund • \\ Malin Lovang • Ebba Hellstrand • Åsa Odelros • \\ Eva Salomon
}

Received: 27 March 2020 / Accepted: 13 January 2021 /Published online: 15 February 2021

(C) The Author(s) 2021

\begin{abstract}
This study investigated manure loads in outdoor paddocks for laying hens and the capacity of two phosphorus $(\mathrm{P})$ retaining materials for reducing leaching from manure in areas with high hen density. Inventories on two commercial farms during 2 years (2017 and 2018) of the impact of hens (groups of 3000 hens) on vegetation, as a proxy for land use by hens, showed that $16-21 \%$ of outdoor area in grassland paddocks and $22-$ $39 \%$ of area in a forest paddock were used by the hens. Sand and limestone were tested as P retention materials in areas with high manure load in a field study during the outdoor season for laying hens (May 1 to October 31 in 2018). The materials were placed on the ground
\end{abstract}

\author{
H. Aronsson $(\triangle)$ \\ Department of Soil and Environment, Swedish University of \\ Agricultural Sciences, Uppsala, Sweden \\ e-mail: Helena.aronsson@slu.se \\ L. Wahlund · E. Salomon \\ RISE, Uppsala, Sweden
}

M. Lovang

Lovang Lantbrukskonsult AB, Vikingstad, Sweden

E. Hellstrand

Hushållningssällskapet, Vänersborg, Sweden

Å. Odelros

Hedesunda, Sweden
( $0.2 \mathrm{~m}$ deep bed, $3.3 \mathrm{~m}$ wide) outside the pop-hole in paddocks with 76 hens. The average numbers of hens outdoors were recorded at 9 am and 3 pm daily. There was no significant difference between the materials concerning distribution of hens, and they seemed not to prefer any material more than the other. When cylinders containing the spent materials were exposed to simulated rainfalls in a laboratory study, the P concentrations in drainage water were high for all materials, including a control with gravel $\left(58-136 \mathrm{mg} \mathrm{PO}-\mathrm{P} \mathrm{L}^{-1}\right.$ and $130-197 \mathrm{mg}$ total-P $\mathrm{L}^{-1}$ ). On average, $14 \%$ of manure $\mathrm{P}$ retained in the sand and limestone materials was leached after $100 \mathrm{~mm}$ of simulated rainfall. Thus, these materials may act as physical filters for $\mathrm{P}$ in manure, but to reduce the risk of $\mathrm{P}$ losses to waters during the following winter, they need to be removed from the paddocks and preferably used as potential $\mathrm{P}$ fertilizers on arable land.

Keywords Phosphorus leaching $\cdot$ Poultry manure $\cdot \mathrm{P}$ binding capacity $\cdot$ Lysimeter

\section{Introduction}

Promoting animal welfare is an essential part of organic livestock production and includes allowing animals to spend time outdoors, in order to stimulate natural behavior. For laying hens with access to outdoor runs, 
there are documented animal welfare benefits, although there are also risks associated with infections, hygiene, imbalanced diets and predation (Knierim 2006). Moreover, organic egg production enterprises face challenges in combining outdoor runs with environmental issues, such as risk of phosphorus $(\mathrm{P})$ and nitrogen $(\mathrm{N})$ losses to the environment. Nutrient losses from agriculture, especially $\mathrm{P}$, severely affect water bodies by causing eutrophication. Manures constitute major nutrient flows in the agricultural system, so livestock density and manure treatment are important factors in the magnitude of the losses (Svanbäck et al. 2019).

The European Union (EU) regulatory system (Commission Regulation (EC) No 889/2008 2008) requires a paddock area of $4 \mathrm{~m}^{2}$ per bird in organic poultry production, which is partly based on the maximum permissible load of $170 \mathrm{~kg}$ total $\mathrm{N} \mathrm{ha}^{-1}$ from animal manure according to the EU Nitrates Directive (EC Council Directive 91/676/EEC 1991). Where the climate requires an indoor season, e.g., in Sweden and Finland, rotation between paddocks during the outdoor season is not mandatory.

Although it is possible to create attractive areas in paddocks, e.g., with roofed shelters, straw bales and trees (Dawkins et al. 2003; Riber et al. 2018), outdoor runs with large groups of hens are often poorly used, and the hens are not evenly distributed over the area. There is reported to be a negative correlation between group size and numbers of hens staying outside at any specific time (Bubier 1998; Hegelund et al. 2005; Chielo et al. 2016) with a breakpoint at a group size of about 500 (Grigor 1993). The amount of birds staying outside is not necessarily less in large groups than in smaller groups but they may be outside less frequently and during shorter periods (Gebhardt-Henrich et al. 2014). The proportion of hens staying outside is typically around 35-40\% in groups with less than 1000 individuals, while often around 5-12\% in larger groups (e.g., 3000 individuals). For large groups, $20-40 \%$ of hens outdoors have also been reported, representing what appear to be optimal conditions (Bubier 1998; Zeltner and Hirt 2003; Hegelund et al. 2005; Chielo et al. 2016). The spatial distribution of birds in paddocks is reflected by a steep gradient of nutrient load in the paddocks with distance away from the hen house. Wiedemann et al. (2018) found, for groups of 250022,000 birds, that $80 \%$ of the manure was deposited within $25 \mathrm{~m}$ of the house, while at a distance of more than $50-70 \mathrm{~m}$ from the house the vegetation was unaffected by grazing.
Nutrients, especially $\mathrm{P}$ which is quite stable in a mineral soil, will accumulate over time close to the hen house as observed by Kratz et al. (2004). Since there is a correlation between soil $\mathrm{P}$ content and water-soluble $\mathrm{P}$ (Börling et al. 2004), continuous use of paddocks will increase the risk of $\mathrm{P}$ leaching over time. Mobile houses are a possible solution for smaller systems, by enabling movement to new areas. Rotations could partly solve the problem by recovery and harvesting of vegetation (Kratz et al. 2004), but this is hardly possible for the area closest to the hen house. Constructed paddocks with treatment units for water runoff have been suggested for high load areas (Wiedemann et al. 2018). Another possible measure is to use materials with $\mathrm{P}$ sorption capacity in areas with high manure load, in order to retain $\mathrm{P}$ and reduce leaching. A wide variety of $\mathrm{P}$ sorbing materials are available; e.g., industrial byproducts such as slags and different types of minerals, limestones, and sand products are currently used for wastewater treatment (Cucarella and Renman 2009). If used on the ground, a material must meet certain criteria in order to avoid negative effects on animal welfare and egg quality, and to comply with the regulations for organic agriculture.

Organic eggs are in high demand in Sweden, but due to lack of empirical data, there is a knowledge gap to make accurate environmental risk assessments of nutrient leaching from paddocks, and to suggest appropriate measures. This is currently hampering expansion of organic laying hen production systems in Sweden. Therefore, the present study was initiated to assess the problem of manure load in paddocks and possible measures to reduce $\mathrm{P}$ leaching.

In the first part of the study, an inventory was conducted on farms in order to study the actual use of outdoor areas by laying hens and manure distribution from the hen house exit and beyond. In the second part, two types of $\mathrm{P}$ retaining materials were laid in beds outside the hen house in a field study, in order to test their potential effect in reducing $\mathrm{P}$ leaching from manure deposition. The materials were evaluated with respect to $\mathrm{P}$ accumulation, comfort for the hens, and in terms of impact on egg production. In the third and final part of the study, the $\mathrm{P}$ retaining capacity of the materials after the outdoor season and was assessed in a laboratory study with simulated rainfall events. Two materials, sand and limestone were tested, where the limestone material $\left(\mathrm{CaCO}_{3}\right)$ was hypothesized to retain $\mathrm{P}$ by chemical adsorption, while the sand (origin from granite) was only expected to act as a physical filter. 


\section{Materials and methods}

Inventory on farms

For examining the hen and manure distribution in paddocks, two organic farms in different parts of southern Sweden were studied. It was assumed that the hens' distribution pattern in the paddocks reflected the distribution of excretions (Menzi et al. 1997). On both farms, the hens were of the breed Bovans robust (Gallus gallus domesticus). On both farms, the hens were distributed in six paddocks, with 3000 hens in each group, giving a total flock size of 18,000 hens, a common building size for commercial organic egg producers in Sweden. The six paddocks were separated with fences, placed fanshaped from the hen house exit and beyond. The paddocks were around 150-200 m long. On both farms, 9000 hens were allowed to enter the grazing outdoor paddocks with total area of 3.6 ha $\left(4 \mathrm{~m}^{2}\right.$ per hen), on each side of the hen house. Over $0-5 \mathrm{~m}$ from the hen house, the soil was covered with gravel. On Farm A, the hen house was surrounded by flat open grassland, with roofed shelters, shrubs of Japanese rose (Rosa rugosa), and hedges of artichokes (Cynara cardunculus), in order to stimulate outdoor activity. On Farm B, one side of the house faced flat grassland with some trees and roofed shelters. The other side faced a forest area, with young birch trees (Betula pendula) from 8 to $40 \mathrm{~m}$ away, and then mature forest in the rest of the paddock, dominated by Norway spruce (Picea abies).

In two study years (2017 and 2018), inventories were conducted in September or October, which is the end of the outdoor season for the farms. On Farm B, only the forest side was studied in 2017, since no hens were present on the grassland side that year. The distribution of hens was studied indirectly, by measuring their impact on vegetation, in order to also estimate the spatial distribution of nutrient load deposited with manure. Assessing the impact on vegetation gave an integrated measure for the whole season, from April until September or October. It did not give information about actual numbers of hens outdoors or amounts of manure deposited. For the inventory, maps were downloaded from Google maps, used to define total paddock area and areas for the different groups, and to document the field observations. The first step was to grade the degree of vegetation cover of the ground in four classes $(0-25 \%$, $26-50 \%, 51-75 \%, 76-100 \%)$. In order to avoid discrepancies due to individual assessment, the same persons did the inventories in all areas and at both occasions. For assessment in the areas with trees and bushes, only the ground was considered, irrespectively of the tree crowns and foliage. Preliminary results showed that the vegetation classes $26-50 \%$, and $51-75 \%$ were almost nonexistent while the classes $0-25 \%$ and $76-100 \%$ were dominating. As a second step, notes were also made of the height of the grass, traces of hens moving through the grass (trampling, feathers and droppings), and how far these traces could be observed. Based on the observations of vegetation ground cover and traces of hens in the vegetation, the following four zones for hen impact on vegetation were identified: (1) high hen impact: bare soil or bare soil with single green plants (0-25\% vegetation cover); (2) medium hen impact: single bare soil spots in more or less intact vegetation, often heavily grazed (mainly 76-100\% vegetation cover); (3) low hen impact: few traces of hens in otherwise unaffected vegetation; (4) no hens: no visible traces.

\section{Field study}

The two P retaining materials, sand and limestone, were selected among a wide variety of possible materials, evaluated for criteria concerning $\mathrm{P}$ retention capacity, compatibility with regulations for organic agriculture, cost, and potential effects on egg production and animal health. This was done during a workshop, including representatives from the poultry sector, advisors, researchers and authorities. Both materials chosen were approved as feed additives for organic agriculture which was relevant from the perspective that hens would probably eat of them.

The study was conducted in 2018 at the Swedish livestock research center east of Uppsala during May 1 to October 31. Nine paddocks were used, each with width $3.4 \mathrm{~m}$ and length $19.9 \mathrm{~m}$. The animal density was high, resulting in $1.1 \mathrm{~m}^{2}$ outdoor area per bird, in order to ensure intensive use of the materials. In April, a $0.2 \mathrm{~m}$ thick bed of sand (granite) or limestone $\left(\mathrm{CaCO}_{3}\right)$, both with particle diameter $0-4 \mathrm{~mm}$, was placed on the ground, just outside the pop-hole $(0-3.3 \mathrm{~m})$ in each paddock. The material covered the whole width of the paddock. The materials were allocated randomly within three blocks of the paddocks, with three replicates. Gravel (particle diameter 6-20 mm) was used as a control. Beyond the material bed, the soil (low-medium clay content) in the paddock was covered with grass and herbs in April. In May, only a few living plants were left 
and thereafter no or very few living plants were visible until October. The spring and summer weather were extremely dry and hot, compared to normal for the site and period (SMHI 2018).

The hens of the breed Bovans Robust (Gallus gallus domesticus) were reared according to organic standards and brought to the layer house at age 16 weeks. Before the experiment began, the birds were habituated to the paddock for 4 weeks. By the end of the experiment, the hens were 46 weeks old. During the experimental period, each group included 75 laying hens and one rooster with access to one paddock $24 \mathrm{~h}$ a day. The hens were fed indoors with organic feed and also had access indoors to water, nests and perches. The house was illuminated by artificial light in times of insufficient daylight. The distribution of hens in paddock was recorded at 9 am and 3 pm daily, by counting numbers of hens and documentation in a protocol. It was conducted for three sub-areas in the paddock: close to hen house ( 0 $3.3 \mathrm{~m})$, middle of the paddock (3.3-6.8 m), and farthest away from hen house (6.8-19.9 m). Five scoring classes were used for recording number of hens: no hens, 1-10 hens, 11-25 hens, 26-50 hens, and 51-75 hens. Once a month, ten randomly selected hens per group were individually scored for signs of feather pecking and injuries on feet according to guidelines used by advisors on commercial farms, to assess animal health. Egg production, food consumption and flock health were recorded continuously.

Before and after the outdoor season, the soil in the three sub-areas in each paddock was sampled for analysis of $\mathrm{P}$ extracted with ammonium lactate (P-AL), which is the analytical method commonly used in Sweden for estimation of plant-available P in the soil. An auger ( $2 \mathrm{~cm}$ diameter) was used to take soil samples from 0 to $0.1 \mathrm{~m}$ depth. Ten samples, distributed over each sub-area, were combined in a bucket, mixed and stored deep frozen until analysis. Also the sand and limestone materials were sampled when collecting material for the laboratory study, but it was not possible to analyze the gravel due to the size distribution (6-20 mm diameter). The two test materials were analyzed for total-P (ICP-OES spectrometry after extraction with nitric acid) and P-AL (Egnér et al. 1960). The initial P content of the sand $\left(540 \mathrm{mg} \mathrm{kg}^{-1}\right.$ ) was subtracted from the value measured in the spent material. All analyses were performed at the Department of Soil and Environment, Swedish University of Agricultural Sciences.
Laboratory study

In October, spent sand, limestone, and gravel materials were collected in PVC cylinders $(0.2 \mathrm{~m}$ diameter, $0.2 \mathrm{~m}$ depth), two from each paddock, (6 per treatment) for a lysimeter study with simulated rainfalls in an indoor mobile sprinkler system (described by Liu et al. 2012).

The lysimeter cylinders were placed in stainless steel trays with narrow openings and a removable metal mesh covered with a polyamide cloth filter, in order to prevent loss of large particles. Flow of water on the outside of the cylinder to the steel tray was prevented by use of tight canvas caps that covered the gap. The drainage water from each cylinder was conducted through a polyethylene tube to a plastic bottle on a shelf under the bench where cylinders were placed. Samples were collected manually. For irrigation, hydraulic atomizing fine spray nozzles with drop diameter $0.07-0.10 \mathrm{~mm}$ and capacity $7 \mathrm{~L} \mathrm{~h}^{-1}$ were used, where the desired irrigation intensity $\left(\mathrm{mm} \mathrm{h}^{-1}\right)$ was achieved by adjustment of the working time for the sprinklers, using a data logger. The water used for irrigation had the following composition: $0.58 \mathrm{~g}$

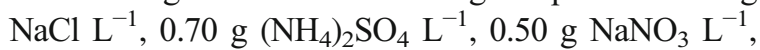
$0.57 \mathrm{~g} \mathrm{CaCl}_{2} \mathrm{~L}^{-1}$ and $0.95 \mathrm{ml} \mathrm{HCl} \mathrm{L}^{-1}$, in order to mimic ionic composition of rainwater (Liu et al. 2012).

The cylinders were exposed to rain simulations, corresponding to $25 \mathrm{~mm}$ per day, with an intensity of $5 \mathrm{~mm} \mathrm{~h}^{-1}$ during $5 \mathrm{~h}$. This was done over 4 days to give a total of $100 \mathrm{~mm}$, which was intended to represent normal rainfalls in autumn. Drainage water from each of the four rain events was collected over-night and analyzed for total-P and phosphate $\mathrm{P}\left(\mathrm{PO}_{4}-\mathrm{P}\right)$. Total-P concentrations were determined colorimetrically on unfiltered samples after oxidation with sulfuric acid and potassium persulfate. The concentrations of $\mathrm{PO}_{4}-\mathrm{P}$ were also determined colorimetrically on filtered samples $(0.2 \mu \mathrm{m})$ without oxidation. Water samples were analyzed at the Department of Aquatic Sciences and Assessment, Swedish University of Agricultural Sciences.

Phosphorus sorption capacity of the sand and limestone materials before start was determined by $\mathrm{P}$ adsorption isotherms, adapted to Langmuir (Bolster and Hornberger 2007). The gravel was assumed to have no P sorption capacity.

Statistical analyses

For statistical analysis of hen distribution in the field study, a general linear mixed model was used with 
treatment (sand, limestone, gravel), week, and sub-area within paddock as fixed factors and block $(N=3)$ containing paddock as random factor. All interactions between the three fixed factors were included, but nonsignificant interactions were removed one at a time. As the repeated observations of hen distribution were made over time for 26 consecutive weeks, a time series structure was included on the error term (repeated measures model). For this, the observations during time period for each of the sub-areas in each paddock were modeled to follow the same autoregressive structure with lag 1 $(A R(1))$. The model was fitted using the procedure MIXED in SAS software (version 9.4, (C) 2002-2012 SAS Institute Inc.). Statistical analysis of soil $\mathrm{P}$ in the field study was made using three-way ANOVA (treatment, subareas, and time of year). For treatment differences of $\mathrm{P}$ concentrations in drainage water and materials in the laboratory study, one-way ANOVA analyses were used. Student's $T$ test was used to compare the amount of $\mathrm{P}$ retained by the sand and limestone materials and proportion of $\mathrm{P}$ leached.

\section{Results}

Inventory on farms

The impact of the hens on vegetation, based on inventories of vegetation ground cover and other traces of hens in growing vegetation, was used as proxy of hen density and manure distribution outdoors. On Farm A, where the hen house was surrounded by flat grassland, there were very distinct zones with decreasing impact on vegetation from the hen house and beyond: high hen impact: 0-9 $\mathrm{m}$ from the hen house; medium hen impact: 9-25 m; low hen impact: $25-60 \mathrm{~m}$; and no hens: $60 \mathrm{~m}$ to fence (130-145 m), with some small variations in the field. The pattern was similar over the 2 years (Table 1 ). In the medium-impact zone, there were some variations as the hedges of artichokes, rose shrubs, and roofed shelters attracted more hens than surrounding grassland. About $80 \%$ of the grassland was not affected at all by the hens, and no traces of dropping or feathers were detected. Only $9 \%$ of the area had medium or high impact of the hens in Farm A. The conditions were similar on the grassland side on Farm B. A different situation was found for the forest side with young birches and Norway spruce, where larger areas had high (both years) and medium (2018) hen impact (16-33\%). Up to $39 \%$ of the total area was used by hens. There was a high hen impact (0-25\% vegetation cover) up to $40 \mathrm{~m}$ from the hen house in 2017 and up to $70 \mathrm{~m}$ in 2018 in the forest paddock on Farm B. In addition, a larger part of the whole outdoor area on the forest side was used by hens, especially in 2018, when hens were exploring not only the young birch stand close to the hen house but also the mature forest of Norway spruce. Here traces of hens were found up to $110 \mathrm{~m}$ from the hen house.

Field study

The weather during the field study in 2018 was unusually hot and dry during the first half of the outdoor period, and cooler with rain showers in the latter half (SMHI 2018) (Fig. 1a). Overall, there were considerable numbers of hens in the paddocks during the whole

Table 1 Area (\% of total outdoor area) showing a high, medium, and low impact of hens on vegetation cover (vc) on two Swedish farms in September/October 2017 and 2018. Each farm had 18,000 hens, divided into nine groups of 3000 hens each

\begin{tabular}{|c|c|c|c|c|}
\hline & High & Medium & Low & No hens \\
\hline & $\begin{array}{l}\text { Bare soil, single green plants } \\
(0-25 \% \mathrm{vc})\end{array}$ & $\begin{array}{l}\text { More or less intact vegetation, } \\
\text { often heavily grazed } \\
(26-100 \% \mathrm{vc})^{*}\end{array}$ & $\begin{array}{l}\text { Few traces of hens in vegetation } \\
(100 \% \mathrm{vc})\end{array}$ & $\begin{array}{l}\text { No visible traces of hens } \\
(100 \% \mathrm{vc})\end{array}$ \\
\hline \multicolumn{5}{|c|}{ Farm A, grassland } \\
\hline 2017 and 2018 & $4 \%$ & $5 \%$ & $12 \%$ & $79 \%$ \\
\hline \multicolumn{5}{|c|}{ Farm B, grassland side } \\
\hline 2018 & $3 \%$ & $6 \%$ & $7 \%$ & $84 \%$ \\
\hline \multicolumn{5}{|c|}{ Farm B, forest side } \\
\hline 2017 & $11 \%$ & $5 \%$ & $6 \%$ & $78 \%$ \\
\hline 2018 & $14 \%$ & $19 \%$ & $6 \%$ & $61 \%$ \\
\hline
\end{tabular}

*) Almost solely in the vegetation cover class $76-100 \%$ 


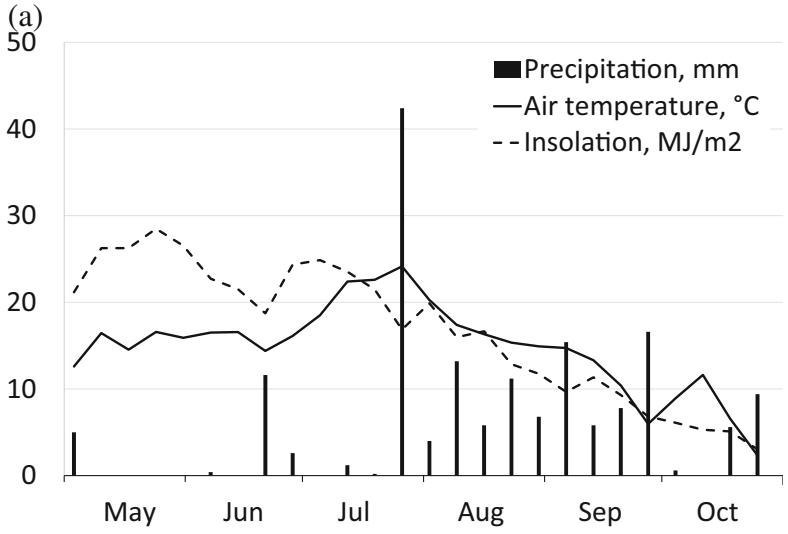

Fig. 1 a Total precipitation, average temperature and average solar insolation per week during the experimental period at the field site (SMHI 2018) and b average number of hens per week in

outdoor season (May 1 to October 31), but after the autumn equinox (September 22), when the daylight hours declined rapidly, outdoor stay visits decreased (Fig. 1b). On average, $43 \%$ of the hens were outdoors in May and 26\% in October.

There was no significant difference in average number of hens outdoors at 9 am and $3 \mathrm{pm}$, or between paddocks with sand, limestone, and gravel materials $(P>0.05)$. This indicated that the hens did not prefer or avoid a certain material compared with the others. There were on average significantly more hens $(P<0.001)$ on the subarea close to the house $(0-3 \mathrm{~m})$ than on sub-areas in the middle $(3-7 \mathrm{~m})$ and farthest away $(7-20 \mathrm{~m})$ from the house, from May 3 to September 3 (Fig. 1b). There was a small roof $1.5 \mathrm{~m}$ long over each pop-hole, giving shade and shelter, during the hot sunny summer. From midSeptember, the differences in average number of hens between sub-areas were smaller with few significant differences, indicating that the hens were more evenly distributed over the paddock area. The hens' preference for different sub-areas thus changed over the experimental period, with a marked change in distribution behavior occurring after a weather change to more rain and moist conditions in late July. However, during rainy observation times, the hens were not outdoors.

Bird health status was considered to be good in all groups. There was some feather pecking at the end of the experiment and some injuries with inflammatory infections to the feet, but there were no differences in incidence of injuries between the materials tested. Egg production was compatible with potential production characteristics of the breed Bovans Robust in free-range egg systems indoors (Table 2).

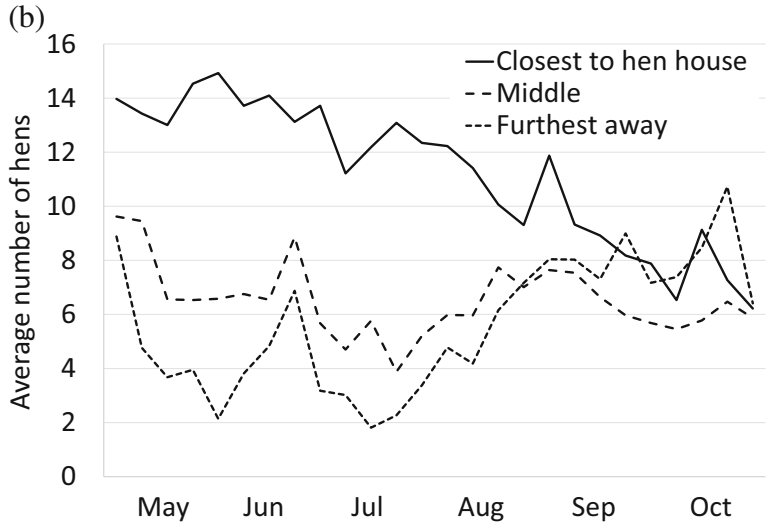

three sub-areas within the paddocks; close to hen house (0-3 m), middle $(3-7 \mathrm{~m})$ and farthest away $(7-20 \mathrm{~m})$

Measurements of easily soluble P (P-AL) in the sand and limestone materials and in soil in the paddocks revealed a significant accumulation $(P<0.05)$ of $\mathrm{P}$ with manure in all three sub-areas from May 1 until October 31. There were also differences between the sub-areas on October 31 (Fig. 2), where the area beyond $7 \mathrm{~m}$ from the hen house had significantly lower values for easily soluble $\mathrm{P}$ than within the first $7 \mathrm{~m}$.

\section{Laboratory study}

Tests on the two paddock materials, sand and limestone, using $\mathrm{P}$ adsorption isotherms revealed that the sand had very low $\mathrm{P}$ binding capacity ( $\operatorname{Smax}=170 \mathrm{mg} \mathrm{kg}^{-1}$ ), as expected, while limestone had much higher capacity $\left(\operatorname{Smax}=10,800 \mathrm{mg} \mathrm{kg}^{-1}\right)$. Despite this, exposure to simulated rain events resulted in very high $\mathrm{P}$ concentrations in water draining from the sand, limestone and control (gravel) lysimeters (on average $58-136 \mathrm{mg} \mathrm{L}^{-1}$ $\mathrm{PO}_{4}-\mathrm{P}$ and $130-197 \mathrm{mg} \mathrm{L}^{-1}$ total-P) (Table 3). Thus, the limestone obviously did not provide any substantial protection against $\mathrm{P}$ losses, despite its high theoretical adsorption capacity. There were no significant differences in drainage water $\mathrm{P}$ concentrations between the two materials of sand and limestone. Concentration of $\mathrm{PO}_{4}-\mathrm{P}$ in water draining from the control (gravel) behaved very differently from the others, with highest values at the first event and then decreasing concentrations, indicating that the gravel was not able to retain $\mathrm{P}$ to the same extent as sand and limestone (Table 3). Moreover, the drainage water from gravel cylinders was dark brown compared with yellow colors in water draining from sand and limestone. In water draining 
Table 2 Potential production characteristics in free-range egg production indoors by the breed Bovans Robust (Source: producers' manual) and performance of hens in the control (gravel) and in the phosphorus retention material (sand, limestone) treatments

\begin{tabular}{|c|c|c|c|c|}
\hline \multirow[t]{2}{*}{ Characteristics } & \multirow[t]{2}{*}{ Manual } & \multicolumn{3}{|c|}{ Treatments } \\
\hline & & Control & Sand & Limestone \\
\hline Summary eggs hen ${ }^{-1}$ week $16-45$ & 166 & 193 & 189 & 189 \\
\hline Layed eggs at week $45, \%$ & 92 & 91 & 89 & 89 \\
\hline Average egg weight at week $45, \mathrm{~g}$ & 64 & 63 & 63 & 63 \\
\hline Consumed feed hen ${ }^{-1} \&$ day $^{-1}$ at week $45, \mathrm{~g}$ & 111 & 118 & 118 & 121 \\
\hline
\end{tabular}

from the gravel cylinders, $\mathrm{PO}_{4}-\mathrm{P}$ constituted $40 \%$ of total $\mathrm{P}$, while it constituted $65 \%$ of total-P on drainage water from the test materials. This indicated that larger amounts of organic $\mathrm{P}$ was lost from the gravel cylinders.

The total amount of manure $P$ retained by the two tested materials were similar, on average $740 \mathrm{mg} \mathrm{P} \mathrm{kg}^{-1}$, but the proportion of the $\mathrm{P}$ leached during simulated rainfalls was significantly $(P<0.05)$ lower for the limestone than from the sand (Table 3). The accumulation in gravel was not possible to analyze due to the coarse texture.

\section{Discussion}

The impact of hens on vegetation on the two farms showed a steep gradient with distance from the hen house, with the highest hen impact, and thereby load of manure, appearing to occur within $10 \mathrm{~m}$ from the house in the outdoor areas on grassland, which constituted only $3-4 \%$ of the total area. Another $5-6 \%$ of the outdoor area (up to around $25 \mathrm{~m}$ from the hen house) was also highly affected by hens. These results confirm findings in other studies and thus seem to be representative for groups of 3000 birds (Wiedemann et al. 2018). Use of P-retaining material in areas close to the house (within $10 \mathrm{~m}$ ) could therefore be a viable way to collect the load of nutrients contained in hen manure.

In the forested area, studied on one farm, the situation was somewhat different. It was obvious that young forest vegetation constituted a shelter and attracted the hens, which was in agreement with, e.g., Hellwing et al. (2017). The zone where the hens had a large impact on

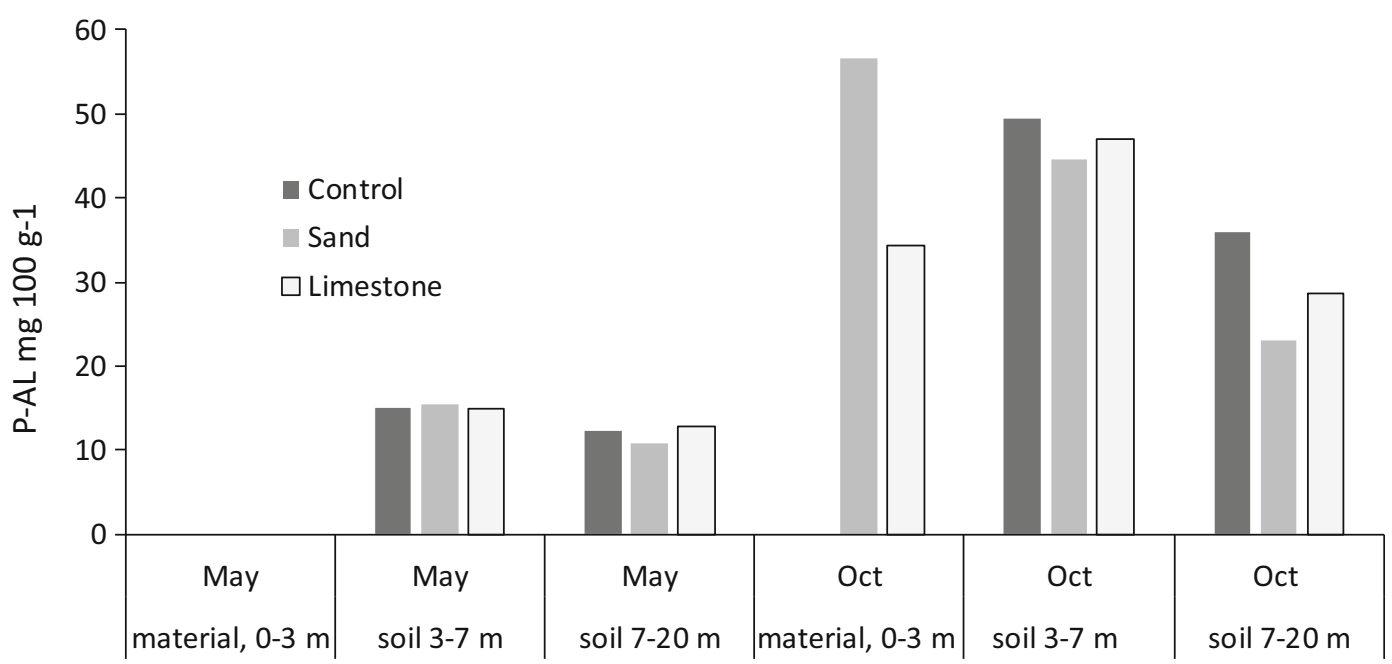

Fig. 2 Mean amount of P-AL (easily soluble) before the outdoor season (May 1) and after (October 31) in sub-areas within the paddocks (0-3 $\mathrm{m}, 3-7 \mathrm{~m}$ and 7-20 $\mathrm{m}$ from the hen house). The test materials $(0-3 \mathrm{~m})$ contained no soluble P on May 1 . The control was not possible to analyze due to the coarse texture. There were significantly smaller P amounts on May 1 than on October 31, and significantly smaller amounts in subarea $7-20 \mathrm{~m}$ on October 31 than in the other sub-areas 
Table $3 \mathrm{P}$ concentrations in drainage water from cylinders exposed to four rain events $(4 * 25 \mathrm{~mm})$, amounts of Total-P in cylinder materials and proportion leached. Superscript letters indicate significant differences between treatments $(\mathrm{p}<0.05)$, and standard deviations are given within brackets. The gravel material in the control was not possible to analyze due to the coarse texture

\begin{tabular}{|c|c|c|c|c|c|c|c|c|}
\hline & \multicolumn{6}{|c|}{ Drainage water, $P$ concentrations, $\mathrm{mg} \mathrm{L}^{-1}$} & \multirow{2}{*}{$\begin{array}{l}\text { Total-P in } \\
\text { cylinders, } g\end{array}$} & \multirow{2}{*}{$\begin{array}{l}\text { Proportion total-P } \\
\text { leached, } \%\end{array}$} \\
\hline & $\begin{array}{l}\mathrm{PO}_{4}-\mathrm{P} \\
\text { Event } 1\end{array}$ & $\begin{array}{l}\mathrm{PO}_{4}-\mathrm{P} \\
\text { Event } 2\end{array}$ & $\begin{array}{l}\mathrm{PO}_{4}-\mathrm{P} \\
\text { Event } 3\end{array}$ & $\begin{array}{l}\mathrm{PO}_{4}-\mathrm{P} \\
\text { Event } 4\end{array}$ & $\begin{array}{l}\mathrm{PO}_{4}-\mathrm{P} \\
\text { Mean }\end{array}$ & $\begin{array}{l}\text { Total P } \\
\text { Mean }\end{array}$ & & \\
\hline Sand & $97(18)^{\mathrm{a}}$ & $135(45)^{\mathrm{a}}$ & $161(69)^{\mathrm{a}}$ & $150(68)^{\mathrm{a}}$ & $136(56)^{\mathrm{a}}$ & $197(71)^{\mathrm{a}}$ & $641(129)^{\mathrm{a}}$ & $18(6.8)^{\mathrm{a}}$ \\
\hline Limestone & $86(49)^{\mathrm{a}}$ & $132(63)^{\mathrm{a}}$ & $133(75)^{\mathrm{a}}$ & $110(59)^{\mathrm{a}}$ & $115(61)^{\mathrm{a}}$ & $163(75)^{a b}$ & $839(237)^{a}$ & $11(3.0)^{b}$ \\
\hline Control & $95(25)^{\mathrm{a}}$ & $30(16)^{b}$ & $46(27)^{\mathrm{a}}$ & $59(27)^{\mathrm{a}}$ & $58(33)^{\mathrm{b}}$ & $130(36)^{b}$ & & \\
\hline
\end{tabular}

vegetation was much wider, up to $70 \mathrm{~m}$ during the second study year. The effect on manure load of having a smaller area with high hen impact in grassed paddocks compared with a larger area with a lower impact in the forest paddock was not measured. It can be assumed that a distribution of hens over a larger area may result in lower load per area unit if the number and duration of outdoor visits by hens remains the same. However, it seems reasonable to assume that a medium-high impact on vegetation reflects larger number of hens, and thereby a larger total load of manure in the forest paddock. Movement of some hens to greater distances may trigger other hens to follow, resulting in more hens outdoors (Grigor 1993). It was obvious that the forested area was more appealing than the grassland and offered a more attractive environment that promoted more utilization of the outdoor area, which is what is desired according to the principles for organic animal systems.

The two $\mathrm{P}$ retention materials tested were chosen based on different criteria such as cost, availability on market and possibility for use in organic agriculture today. This, in combination with minimizing the risk of negative effects on bird health and toxic substances in the eggs, limited the number of possible options. For example, materials with high $\mathrm{pH}$, as different types of slag products and calcium oxide having a $\mathrm{pH}$ of 10 or above, had to be excluded from the list of potential materials to be placed on the ground, where the hens could reach them. The results verified that the sand and limestone materials were suitable with respect to comfort for the hens. The hens used them intensively for sand-bathing and scratching, and there were no indications of any negative impact on health or production. There was no difference between the test materials concerning hens' use preferences. After a change in weather conditions, from hot and dry to normal summer temperatures, the distribution patterns of the hens in the outdoor paddocks also changed. This could have been due to the change in the weather, but also to other factors changing hen behavior, such as hen age and experience of outdoor conditions. All materials, including the gravel, were intensively used by the hens during the whole season.

There was substantial accumulation of $\mathrm{P}$ with manure in the field study paddocks, especially within the first $7 \mathrm{~m}$ from the hen house. This suggests that the Pretaining materials should have covered this high-impact area. The high load of $\mathrm{P}$ was not surprising since bird density was high $\left(1.1 \mathrm{~m}^{2}\right.$ per hen compared with 4 $\mathrm{m}^{2}$ under EU regulations (Commission Regulation (EC) No 889/2008 2008) and many hens were observed outdoors. The hens were using the whole paddock area. The proportions of hens outside (26-43\%) were comparable to that reported in other studies of smaller groups. For example, groups of 500 birds were studied by Bubier (1998) and Zeltner and Hirt (2003), who found that $42 \%$ and $22 \%$ of the hens in the flock were outside, respectively. Hegelund et al. (2005) made predictions based on factors such as group size, age, weather conditions, time of day and season, and concluded that for group sizes of 0-1000, 1000-3000 and > 3000, outdoor stays by $35-40 \%, 25 \%$, and $15-20 \%$ of birds represent optimal conditions.

$\mathrm{P}$ accumulated in the materials proved to be highly vulnerable to losses when exposed to simulated rainfall, resulting in very high concentrations of $\mathrm{P}$ in drainage water, although only $11-18 \%$ of the total $\mathrm{P}$ content was lost after $100 \mathrm{~mm}$ of simulated rainfall. The $\mathrm{P}$ concentrations in drainage water were also high initially for the gravel material used as control, but they declined quickly over time. The drainage water was dark brown from the gravel cylinders while it was 
yellow from the others. This indicated that manure particles were more efficiently washed out from the gravel and that it did not work as a physical filter to the same extent as the other materials. However, it was not possible to evaluate how much had been lost from the material already out in the paddocks. It was expected that the very high theoretical binding capacity of the limestone $\left(10,800 \mathrm{mg} \mathrm{kg}^{-1}\right)$ would result in greater retention by adsorption of $\mathrm{P}$ in the limestone bed than in the sand bed. The proportion of $\mathrm{P}$ lost during simulated rainfall events was significantly less from the limestone (11\% compared with $18 \%$ ) which indicated somewhat larger retention capacity, but in practice the differences were small. There were no significant differences in $\mathrm{P}$ accumulation out in the paddocks and no differences in measured losses during simulated rainfall events. The conclusion was that sand and limestone both functioned similarly as physical filters for $\mathrm{P}$ during the outdoor season but that, in order to reduce the risk of losses to waters during winter precipitation, they need to be removed in autumn. A lysimeter study, where there is no percolation of water through a subsoil, represents a worst case scenario for the system. In the field, the soil volume under the bed material would act more or less efficiently as a filter for $\mathrm{P}$, depending on its $\mathrm{P}$ binding capacity and water pathways through the soil. However, this constitutes a considerable risk in the long term, since $\mathrm{P}$ leaching will increase when the $\mathrm{P}$ saturation of the soil increases (Börling et al. 2004; Tarkalson and Mikkelsen 2004). The materials of sand and limestone may be used as fertilizers on arable land after being used in the paddock, since they are approved for use in organic agriculture. This would combine improved circulation of $\mathrm{P}$ on the farm, reduced risk of $\mathrm{P}$ accumulation in the soils around the hen house, and thereby reduced risk of $\mathrm{P}$ leaching.

\section{Conclusions}

Provision of forest as an outdoor area, compared with open grassland, seems to stimulate outdoor activity among hens. Inventories on farms showed that a forested paddock with young trees close to the hen house had considerably larger areas intensively used by hens, and a wider distribution of hen activity over the outdoor area, than open grassland paddocks.
Phosphorus load from hen manure was considerable within $7 \mathrm{~m}$ from the hen house in a field study. A 0.2-mdeep retention bed of sand or limestone was intensively used by the hens and successfully retained manure $\mathrm{P}$ during the summer, without any negative impact on hen health, egg production and quality.

However, both materials only worked as physical filters and $\mathrm{P}$ retained in the materials was vulnerable to leaching losses following rainfall. In order to avoid leaching later on, the materials must be removed from the paddock, and preferably be used as fertilizers, thereby combining reduced risk of $\mathrm{P}$ leaching losses with improved circular flows of $\mathrm{P}$.

Code availability Not applicable.

Author contribution According to submission guidelines.

Funding Open Access funding provided by Swedish University of Agricultural Sciences. The study was financed by The Swedish Farmers' Foundation for Agricultural Research.

Data availability Not applicable.

Compliance with ethical standards

Ethics approval The field study at a research station was examined and approved for ethical considerations by the Swedish Board of Agriculture.

Consent for publication Not applicable.

Conflict of interest The authors declare no competing interests.

Open Access This article is licensed under a Creative Commons Attribution 4.0 International License, which permits use, sharing, adaptation, distribution and reproduction in any medium or format, as long as you give appropriate credit to the original author(s) and the source, provide a link to the Creative Commons licence, and indicate if changes were made. The images or other third party material in this article are included in the article's Creative Commons licence, unless indicated otherwise in a credit line to the material. If material is not included in the article's Creative Commons licence and your intended use is not permitted by statutory regulation or exceeds the permitted use, you will need to obtain permission directly from the copyright holder. To view a copy of this licence, visit http://creativecommons.org/licenses/by/4.0/.

\section{References}

Bolster CH, Hornberger GM (2007) On the use of Langmuir equations. Soil Sci Soc Am J 71(6):1796-1806 
Börling K, Ottabong E, Barberis E (2004) Soil variables for predicting phosphorus release in Swedish noncalcareous soils. J Environ Qual 33:99-106

Bubier NE (1998) Movement of flocks of laying hens in and out of the hen house in four free range systems. Br Poult Sci 39(S1): 5-6. https://doi.org/10.1080/00071669888025

Chielo LI, Pike T, Cooper J (2016) Ranging behavior of commercial free-range laying hens. Animals 2016(6):28. https://doi. org/10.3390/ani6050028

Commission Regulation (EC) No 889/2008 (2008) Laying down detailed rules for the implementation of Council Regulation (EC) No 834/2007 on organic production and labelling of organic products with regard to organic production, labelling and control. Official Journal Euorpean Union, L250:11. http://eur-lex.europa.eu/legal-content/EN/TXT/PDF/?uri= CELEX:32008R0889\&from $=\mathrm{EN}$

Cucarella V, Renman G (2009) Phosphorus sorption capacity of filter materials used for on-site wastewater treatment determined in batch experiments-a comparative study. J Environ Qual 38:381-392. https://doi.org/10.2134/jeq2008.0192

Dawkins MS, Cook PA, Whittingham MJ, Mansell KA, Harper AE (2003) What makes free-range broiler chickens range? In situ measurement of habitat preference. Anim Behav 66:151160. https://doi.org/10.1006/anbe.2003.2172

EC Council Directive 91/676/EEC (1991) Concerning the protection of waters against pollution caused by nitrates from agricultural sources. Off J Eur Union L 375, 31/12/1991: 0001-0008

Egnér H, Riehm H, Domingo WR (1960) Untersuchungen über die chemische Bodenanalyse als Grundlage für die Beurteilung des Nährstoffzustandes der Boden. In: II Chemische Extraktionsmethoden zur Phosphor- und Kaliumbestimmung, 26th edn. Kungliga Landbrukshogskolans Annaler, German, pp 199-215

Gebhardt-Henrich SG, Toscano MJ, Fröhlich EKF (2014) Use of outdoor ranges by laying hens in different sized flocks. Appl Anim Behav Sci 155:74-81

Grigor PN (1993) Use of space by laying hens: social and environmental implications for free-range systems. Dissertation, University of Edinburgh

Hegelund L, Sørensen JT, Kjær JB, Kristensen IS (2005) Use of the range area in organic egg production systems: effect of climatic factors, flock size, age and artificial cover. Br Poult Sci 46(1):1-8
Hellwing ALF, Petersen JS, Steenfeldt S (2017) Performance and range use of organic broilers with access to different vegetation in outdoor areas. In: Francesch M, Torralardona D, Brufau J (eds) Proceedings of the 21 st European Symposium on Poultry Nutrition. Wageningen Academic Publishers

Knierim U (2006) Animal welfare aspects of outdoor runs for laying hens: a review. NJAS 54(2):133-145

Kratz S, Rogasik J, Schnug E (2004) Changes in soil nitrogen and phosphorus under different broiler production systems. J Environ Qual 33(5):1662-1674

Liu J, Aronsson H, Ulén B, Bergström L (2012) Potential phosphorus leaching from sandy topsoils with different fertilizer histories before and after application of pig slurry. Soil Use Manag 28:457-467

Menzi H, Shariatmadaari H, Meierhans D, Wiedmer H (1997) Nähr- und Schadstoffbelastung von Geflügelausläufen. Agrarforschung 4:361-364

Riber AB, van de Weerd HA, de Jong IC, Steenfeldt S (2018) Review of environmental enrichment for broiler chickens. 2018. Poult Sci 97(2):378-396. https://doi.org/10.3382 $/ \mathrm{ps} / \mathrm{pex} 344$

SMHI (2018) Swedish Meteorological and Hydrological Institute. https://www.smhi.se/en. Accessed 23 September 2019

Svanbäck A, McCrackin M, Swaney P, Linefur H, Gustafsson B, Howarth R, Humborg C (2019) Reducing agricultural nutrient surpluses in a large catchment - links to livestock density. Sci Total Environ 648:1549-1559

Tarkalson DD, Mikkelsen LR (2004) Runoff phosphorus losses as related to soil test phosphorus and degree of phosphorus saturation on piedmont soils under conventional and notillage. Commun Soil Sci Plant Anal 35:2987-3007

Wiedemann S, Pratt C, Bliefield N, Mayer DG, Redding MR, McGahan E (2018) Establishing soil nutrient distribution zones across free range egg farms to guide practical nutrient management strategies. Agric Ecosyst Environ 257:20-29

Zeltner E, Hirt H (2003) Effect of artificial structuring on the use of laying hen runs in a free-range system. Br Poult Sci 44(4): 533-537. https://doi.org/10.1080/00071660310001616264

Publisher's note Springer Nature remains neutral with regard to jurisdictional claims in published maps and institutional affiliations. 